\title{
CHANGING THE CULTURE OF E-LEARNING IN HIGHER EDUCATION: MOVING FACULTY FROM INACTION TO ACTION
}

\author{
Maria Elena Corbeil, The University of Texas at Brownsville, mariaelena.corbeil@utb.edu \\ Joseph Rene Corbeil, The University of Texas at Brownsville, rene.corbeil@utb.edu
}

\begin{abstract}
In recent years, universities have been forced to cut resources and even programs that are not enrolling and graduating enough students. To exacerbate the situation, academic programs are experiencing increased competition from in state and out-of-state online institutions that are encroaching into their service areas. In addition, the pressure to increase access and improve learning outcomes while reducing costs is intensifying. University administrators recognize the need to expand online program offerings in order to remain competitive and even survive. While some programs are responding to the call, faculty resistance hampers their ability to put their entire programs online. This article presents a case study of academic program market saturation, describing a fledgling doctoral program and the efforts of a small group of pioneering faculty, determined to continue its growth, by taking it online. A discussion of faculty readiness and future directions are presented, as well as ideas to help move faculty from inaction to action, and for adopting a system-wide culture of high quality e-learning.
\end{abstract}

Keywords: E-learning, Online learning, Distance education,

\section{INTRODUCTION}

Increasingly, universities have been forced to reduce costs, while concurrently being obliged to expand program offerings, as well as registration and graduation rates without sacrificing, but rather improving, quality and competitiveness. Academic programs with low enrollment and/or graduation rates are being cut, or in some cases, completely eliminated. To complicate matters, universities that were once exclusive providers of higher education in their region, are experiencing overwhelming competition from online programs. Administrators and some faculty recognize the need to expand online program offerings in order to remain competitive, and even survive. "Extraordinary pressure is mounting...to address the ever-increasing growth in the costs of higher education and to improve student learning outcomes. Online learning holds great promise to address these issues, but requires these institutions to operate in substantially different ways" [7]. While a few programs are responding to the call, faculty resistance to e-learning hampers their ability to reach perspective students outside of their service area.

Although the university selected for the case study has been involved in distance education since 1997, progress in getting entire programs online has been slow and problematic. With the exception of a handful of intrepid faculty who ventured into e-learning on their own, the majority of university faculty have avoided making the jump to hybrid or fully online, web-based instruction. The resulting piecemeal approach to e-learning development has resulted in dozens of random online courses being offered in nearly every discipline. Indeed, until a few years ago, only two programs were offered $100 \%$ online. Although the number has steadily increased to 12 programs over the past two years, most of these programs are experiencing painfully slow thwarted growth as administrators struggle to find qualified online faculty. In some instances, reluctant faculty are enticed through release time or other extrinsic reward. Other faculty are drafted to teach online against their will. One program that is in dire need of expansion is the recently approved Doctor of Education program in the College of Education.

\section{A CASE STUDY OF ACADEMIC PROGRAM MARKET SATURATION}

This case study describes an example of market saturation for a new Doctor of Education program in a South Texas university located along the United States - Mexico border. The institution has a total student population of 13,836 students, of which $92.7 \%(12,828)$ are Hispanic; $57.7 \%(7,990)$ are female; and, $42.3 \%(5,846)$ are male. Of the total number of enrolled students, 6.8\% (937) are pursuing graduate degrees, and of those students, only $45(0.3 \%)$ are currently pursuing a doctoral degree [10]. 


\section{Issues in Information Systems}

Volume 13, Issue 2, pp. 226-231, 2012

The College of Education offers 26 undergraduate, 7 Master's, and 1 Doctoral degree. Of the 34 programs offered through the College of Education, only one program, the Master of Education in Educational Technology is offered fully online. All of the other programs are offered on campus, with a few courses delivered in hybrid or online formats.

The Doctor of Education (Ed.D.) in Curriculum and Instruction is a 66-hour program that "prepares educators to assume leadership positions in institutions of higher education; and in local, regional, and independent school districts at multiple levels" [9]. It offers specializations in Bilingual Studies, Early Childhood, Educational Leadership, Educational Technology, and Higher Education Teaching. One specialization in Reading was cancelled in January 2012 due to low interest.

The doctoral program originates from the Department of Teaching, Learning and Innovation within the College of Education. This small department has fewer than 20 full-time faculty, yet it consistently yields the highest percentage of graduates of all university programs. These faculty teach the core education and research courses for all of the undergraduate and graduate education degree programs, including the Doctor of Education in Curriculum and Instruction.

Since 2007, a yearly cohort of 15 students has been admitted into the doctoral program. While the pool of qualified candidates was relatively large during the first two years of implementation, the number and quality of applicants has been steadily decreasing year after year. In fact, in the past two years, program coordinators struggled to find enough qualified candidates to form the 2010 and 2011 cohorts.

Despite being only five years old, there are signs that the doctoral program is beginning to reach market saturation. Several factors are contributing to having reached capacity in such a short period of time, including increased competition from a doctoral program in Educational Leadership by a university less than 60 miles away, as well as fully online programs from profit and non-profit institutions beginning to actively recruit students from our region. Combine these factors with the fact that there are only so many jobs available within the region that require a terminal degree, and the pool of qualified candidates continues to dwindle. To further exacerbate the problem, most of the recent graduates have strong cultural and family ties to the area and do not plan to seek employment elsewhere, making it harder for future graduates to find jobs.

If the doctoral program is to survive long enough to establish itself, it is going to have to come up with creative ways to attract news students from farther and farther away. Since most doctoral students are full-time working professionals with family responsibilities, having them drive 60+ miles to attend weekly classes on campus is not an option. The only viable alternative, then, is to bring the classes to them.

Recognizing the inevitability of this reality and the risk of doing nothing, the Bilingual Studies faculty took decisive action by establishing partnerships with two state universities in North East and Central Texas to bring their program to them. Starting in Fall 2012, they will begin to deliver the Bilingual Studies specialization to distant audiences via two-way videoconferencing. The articulation agreements made between the remote sites and the home campus require that a qualified bilingual instructor be present at both remote campuses, as well as at the home campus during all class sessions. Students understand that while a majority of the program will be delivered through video conferencing, they will be required to travel to the home campus several times throughout the duration of the program. Although burdensome, the videoconferencing option is a significant first step in extending the reach of the doctoral program to new audiences. Yet, it is still limited by geography.

Following the Bilingual Studies lead, the Educational Technology program, which already offers all of its doctoral specialization courses $100 \%$ online, is also seeking to extend its reach to new audiences around the state and beyond. Its current reach is limited by the Curriculum \& Instruction core and research courses, which are still taught on campus. While the Educational Technology faculty have considered piggybacking off of the video conferencing sites established by the Bilingual Studies specialization, there is concern that the resources would not be sufficient to 


\section{Issues in Information Systems}

Volume 13, Issue 2, pp. 226-231, 2012

accommodate and sustain both specializations. Therefore, in order to grow, the core and research courses will need to be offered online. However, this solution is not being well received by a significant percentage of the college faculty.

\section{ASSESSING FACULTY RESISTANCE TO E-LEARNING}

The rationalizations for why a significant percentage of the faculty are resistant to online learning are as varied as the instructors themselves. Some faculty have a deeply seeded aversion to online learning based on inaccurate representations of what they perceive e-learning to be. Others oppose e-learning on philosophical grounds or the mistaken belief that online learning is inferior to traditional face-to-face instruction. Other faculty are open to moving into online instruction, but lack the knowledge, skills, and/or time needed to make the transition. Bascow, et al., [1] observed, "while online instruction is growing rapidly at most institutions, skeptics and critics abound. Not everyone is enthusiastic about the growth of technology-mediated teaching" (p. 19).

Efforts in moving the doctoral program online, have thus far, resulted in moderate gains. To move forward, a change in the way we approach the reluctant faculty will be necessary to prepare them to move their courses online. So, after years of placing most of the responsibility (and work) on the faculty who were willing and able, and patiently waiting for the rest of the faculty to adapt, it is time to take a careful look at the unresponsive faculties' readiness for innovation adoption.

Figure 1 below, modified from Hersey and Blanchard's [6] Situational Leadership Model, can be used to represent faculties' readiness for e-learning adoption. All too often, academic programming decisions are made top-down or in a microcosm by those who are already comfortable and skilled at e-learning, with little consideration given to the level of readiness of colleagues, who oftentimes hold key pieces for the full-scale implementation of online programs.

\begin{tabular}{|c|c|c|}
\hline Possibilities & Able & Not able \\
\hline Willing & & \\
\hline Not willing & & \\
\hline
\end{tabular}

Figure 1. Follower readiness as defined by Hersey-Blanchard's (1988) Situational Leadership Model

According to Hersey-Blanchard's [6] Situational Leadership Model, effective leaders adapt their leadership styles according to the level of readiness demonstrated by the followers for a required activity. The theory posits that readiness is composed of a combination of a person's ability (experience, skills, and knowledge) and willingness (confidence, commitment, and motivation). With this knowledge, leaders, in turn can adapt their leadership styles by focusing less on the task at hand, and more on the relationship with the follower. Consider the following character descriptions. They can help to illustrate Hershey and Blanchard's levels of readiness on which elearning faculty and administrators can focus their efforts.

Willie (Faculty 1): Not willing or able to participate. "If you want someone to teach this course online, I'm not that guy."

In response to the Dean's directive to make all graduate core courses available to students in both face-to-face and online formats, the chair approaches the instructor of a research course that is required in all graduate programs and asks him to teach the course online in the upcoming semester. In a panic, the instructor responds, "If you want someone to teach that course online, I'm not that guy!" The reluctant instructor grumbled and protested for several weeks until the department chair relented. 


\section{Issues in Information Systems}

Volume 13, Issue 2, pp. 226-231, 2012

\section{Norm (Faculty 2): Able but not willing to participate. "I like how I teach and have no desire to change."}

Norm, who has many years of teaching experience, is asked by his department chair to teach one of his courses online next semester. Although Norm is fully capable of developing and teaching the class in an online format, he doesn't believe that online instruction is as effective as teaching in front of a live class. The negative stories he has heard from colleagues and students have validated his low opinion of online instruction. His response to the chair is, "If you don't need me to teach this course on campus, then I guess you don't need me." Being tenured, he knows that the chair will eventually give in.

\section{Ms. Ready (Faculty 3): Not able but willing to participate. "What do I have to do to get my courses ready to go online?"}

Ms. Ready hears her students raving about an online class they are taking with another instructor. Intrigued, she presses the students for details. In particular, she wants to know what instructional strategies were used in the delivery of instruction and what the students thought about the experience. She considers her current technical skills and recognizes that she is nowhere near ready to teach online. So, Ms. Ready reaches out to experienced online faculty for advice and assistance, asking, "What do I have to do to get my courses ready to go online?"

\section{Abel (Faculty 4): Willing and able. "We need this course to be taught online? Let's roll!"}

The director of an online graduate program approaches Abel, his colleague, to request a 'huge favor': Would he be willing to teach a new online course next semester for a faculty member who is retiring? Having taken numerous online classes before, and having enjoyed the experience, Abel enthusiastically accepts the challenge. He has confidence in his technological skills and in his understanding of what works best in online courses. His response to the director is, "Of course! When can I get started?"

For over two years, a small team of faculty have tried, and made some slow and steady headway with faculty who were willing/unable or unwilling/unable by establishing an informal mentor program. One or two faculty, who were willing and able, teamed up with faculty who were willing, but who had no experience designing and delivering a course online. This faculty mentorship model has been successful and resulted in learning for all the faculty involved. In fact, in one semester's time, the faculty who participated now have one or more courses fully online. However effective, this progress has been slow. In order for the doctoral program to advance at the pace it needs to survive and grow, the entire faculty need to be ready (willing and able) to offer online courses within the next year.

In trying to design a faculty incentive and support program, we turned to the literature for ideas. In one comprehensive study, Barriers to Adoption of Online Learning Systems in U.S. Higher Education, Bascow et al., [1] made the following recommendations to help reduce resistance and increase faculty participation in e-learning: (a) ensure that there is enough technical support for online faculty; (b) give online faculty incentives; (c) find ways to celebrate the courageous faculty who go first; (d) start with courses that are the most appropriate and can more easily be transformed for online learning environments; (e) ensure that some of the income that is generated from the online courses/programs is shared with the department that is offering them; and (f) establish an administrative unit dedicated exclusively to online programs.

Specifically regarding incentives, Bascow et al., [1], added that since preparing courses and teaching online require an investment of additional time and resources (learning new skills, managing new technologies, etc.) for the faculty, providing an appropriate form of compensation can be very beneficial. They warned, "...financial incentives alone may not be sufficient. Faculty time is the scarcest resource on any college or university campus" (p. 24). This may make release time more appealing to faculty and help reduce the resistance that stems from not having enough time to adequately learn the necessary skills, develop, design, and teach the online courses, while having to fulfill all other responsibilities (ex. service, scholarship, etc.). "I really think the key to all of this will be, how do you support the faculty member" (Seaman, as cited in Guess [5])? With reduced budgets at the national and state level, most 


\section{Issues in Information Systems}

Volume 13, Issue 2, pp. 226-231, 2012

programs have little to no funding for monetary or technology incentives.

\section{OVERCOMING RESISTANCE: MOVING FACULTY FROM INACTION TO ACTION}

In order to entice College of Education faculty who teach doctoral courses to move their courses online, several carrots (incentives), but no sticks (negative consequences) have thus far been implemented. One carrot being proposed is to make online teaching a 'high value' activity under the faculty member's teaching responsibilities. Under this proposal, faculty who teach online would receive extra credit in the area of "Teaching" for their Faculty Workload and Responsibility portfolios. Teaching online would be considered a Category 1 activity, the highest level in a 3-category scale: Category 1 (distinguished), Category 2 (target), and Category 3 (minimum).

Another incentive being considered is a 1-course release during the semester prior to teaching an online course to give faculty additional time to develop their courses. While this incentive is not very popular among some members of the upper administration, it has received mild support from the faculty. An alternative incentive being proposed is to assign online courses more weight in the determination of faculty workload each semester. This model is already used for instructors of teacher preparation field-based courses, which have additional responsibilities and incur extra costs than traditional site-based courses. Under this proposal, which seems to have more faculty support than the previous one, doctoral faculty who teach online courses could satisfy their teaching workloads with two courses, versus the current three.

The idea has been raised of rewarding faculty who teach online with a preferred status when seeking travel funds for conferences and professional development. With travel funds in constant threat of being cut or eliminated, having an advantage when travel funds are distributed can be a strong motivator, and when asked, faculty seem to be generally supportive of the idea. Additional incentives may also involve providing online faculty technologies, such as tablets, laptops, and video cameras. Since currently there are no funds available for the purchase of the equipment, grants would have to be written.

While incentives are a good intermediary step in encouraging some faculty to move from inaction to action, a stronger, more powerful inducement is to foster a change of mindset or culture regarding online instruction. Bascow et al., [1] noted, "...there is no magic bullet. Strategies must be adapted to address the unique circumstances encountered at each institution" (p. 23). By adopting a vision for the future of the College of Education that includes a goal for exploring and enhancing all avenues for instructional delivery, it will challenge faculty to establish guidelines and best practices for the improvement of all modes of instruction, including on site, online, and combinations of both.

\section{SUMMARY AND FUTURE DIRECTIONS}

Developing an organizational attitude that is conducive to educational exploration and innovation is a laborious undertaking and should not be imposed from the top down. Establishing a culture of e-learning within an organization can be facilitated through a series of initiatives and some coordinated effort from all stakeholders. For example, as new faculty are hired, recruiters should be looking for candidates that support the program's goals, and preferably, have experience in designing and teaching online classes. As more faculty begin to teach online, it may serve as an incentive to induce other faculty to give it a try. Department chairs could find creative ways to incentivize the development of new online classes in key areas to maximize their impact. For example, core courses that are shared by multiple programs should be given the highest priority. Online courses, because they are generally more labor and time intensive than traditional courses, should carry more weight on faculty teaching workloads. Lastly, the mission statement of the college could be revised to include e-learning as an essential approach for enhancing the quality, accessibility, and affordability of its programs.

Thankfully, the doctoral program's efforts to increase its availability to broader audiences are not being implemented in isolation. Some progress has been made, at the college, institutional, and system level. At the college level, the Dean is reviewing some of the incentives that have been described in this paper and is considering 


\section{Issues in Information Systems}

Volume 13, Issue 2, pp. 226-231, 2012

them for possible inclusion into the college faculty handbook and for the highest-level of scholarship in the faculty workload portfolio. At the beginning of the year, the Provost also announced the creation of a Provost's Fellow for Distance Education. The Fellow's primary objective will be to identify ways to enhance the quality and availability of online courses throughout the university. This summer, he will present his recommendations to the university administration.

At the system level, the University of Texas System made a commitment supported by funding with the approval of up to $\$ 50$ million dollars to catapult online and blended learning in System universities. In August 2011, The University of Texas System Chancellor, Francisco G. Cigarroa, M.D., noted, "This significant investment approved by the Board of Regents will allow the UT System to leapfrog our current efforts by providing critical financial resources to support a cyber infrastructure that will enable us to help the UT institutions expand their individual capabilities in blended and online learning" [11].

The next phase of this study will be to evaluate the effectiveness of some these initiatives. Roger's Innovation Decision Process Theory [8] will be used as a framework to analyze the stages of e-learning adoption by the College of Education doctoral faculty. It is hoped that the results of this multi-stage study will help inform current and future decisions regarding e-learning program development, faculty training, and incentives in order to facilitate the expansion of program offerings, so the doctoral program, and other programs, can remain competitive and offer students improved access and opportunities.

\section{REFERENCES}

1. Bascow, L. S., Bowen, W. G., Guthrie, K. M., Lack, K. A., \& Long, M. P. (2012). Barriers to adoption of online learning systems in U.S. higher education. ITHACA S+R, Retrieved

from http://www.sr.ithaka.org/research-publications/barriers-adoption-online-learning-systems-us-highereducation

2. Carr, Jr., V. H. (1999). Technology adoption and diffusion. The Learning Center for Interactive Technology. Retrieved from http://www.au.af.mil/au/awc/awcgate/innovation/adoptiondiffusion.htm

3. DeBate, R. D., Cragun, D., \& Severson, H. H., et al., (2011). Factors for increasing adoption of e-courses among dental and dental hygiene faculty members. Journal of Dental Education, 75(5), 589-597. Retrieved from http://www.ncbi.nlm.nih.gov/pmc/articles/PMC3118442/pdf/nihms297972.pdf

4. Fagan M. H. (2011). Using an innovation diffusion theory framework to explore web site adoption by small to medium sized enterprises. Issues in Information Systems, XII(1), 382-391. Retrieved from http://iacis.org/iis/2011/382-391_AL2011_1716.pdf

5. Guess, A. (2008, November 18). With students flocking online, will faculty follow? Retrieved from http://www.insidehighered.com/news/2008/11/18/online

6. Hersey, P., \& Blanchard, K. H. (1988). Management and organizational behavior. NJ: Prentice-Hall.

7. Ithaka News. (2012, May 01). Taking steps toward "Interactive learning online." Retrieved from http://www.ithaka.org/news/taking-steps-toward-"interactive-learning-online"

8. Rogers, E. M. (1995). Diffusion of innovations (4th ed.). New York: The Free Press.

9. The University of Texas at Brownsville. (2012a). Doctoral degree in Curriculum and Instruction promotional flyer.

10. The University of Texas at Brownsville. (2012b). Fast facts. Retrieved from http://www.utb.edu/vpaa/admin/Pages/FastFacts.aspx

11. The University of Texas System. (2011, August 25). Regents authorize $\$ 50$ million investment for UT System institute for transformational learning. Retrieved from http://www.utsystem.edu/news/2011/08/25/regentsauthorize-50-million-investment-ut-system-institute-transformational-learnin 